\title{
Influence of Annealing Temperatures on Nonlinear Optical, Dielectric, Semiconducting Results, and Fermi Level Position for CdIP $\mathrm{P}_{0.3} \mathrm{Te}_{0.97}$ Thin Film
}

\author{
Ahmed Abdel Moez 1,*(D), Medhat A. Ibrahim ${ }^{2}$ (D), Samia A.Gad ${ }^{3}$ (D) \\ 1 Solid-State Electronics Laboratory, Solid State Physics Department, Physical Research Division, National Research \\ Centre, 33 El-Bohouth Street, Dokki, Giza 12622, Egypt; aam692003@yahoo.com (A.A.M.); \\ 2 A Molecular Spectroscopy and Modeling Unit, Spectroscopy Department, National Research Centre, 33 El-Bohouth St., \\ 12622, Dokki, Giza, Egypt; medahmed6@yahoo.com (M.A.I.); \\ 3 Semiconductor Laboratory, Solid State Physics Department, Physical Research Division, National Research Centre, 33 \\ El- Bohouth Street, Dokki, Giza 12622, Egypt; samiagad2000@yahoo.com (S.A.G.); \\ * Correspondence: aam692003@yahoo.com (A.A.M.);
}

Scopus Author ID 57034126200

Received: 13.03.2021; Revised: 1.05.2021; Accepted: 5.05.2021; Published: 10.06.2021

\begin{abstract}
CdP}_{0.03} \mathrm{Te}_{0.97}$ thin films were deposited at room temperature using thermal evaporation and annealed at 100 and $200^{\circ} \mathrm{C}$. The effect of annealing temperature $T_{\text {ann }}$ on both dispersion energy $E_{d}$ and oscillating energy $E_{o}$ were studied. The lattice dielectric constant $\varepsilon_{\mathrm{L}}$ and free carrier concentration/effective mass $\mathrm{N} / \mathrm{m}^{*}$ were calculated for these samples. The values of the first order of moment $\mathrm{M}_{-1}$, the third order of moment $\mathrm{M}_{-3}$, and static refractive index $\mathrm{n}_{\mathrm{o}}$ were determined. Both of dielectric loss $\varepsilon^{\prime}$ and dielectric tangent loss $\varepsilon^{\prime \prime}$ for these films increased with photon energy (hv) and had the highest value higher than the energy gap $E_{g}$. All of the optical parameters such as real part of optical conductivity $\sigma_{1}$, the imaginary part of optical conductivity $\sigma_{2}$ and the relation between Volume Energy Loss/ Surface Energy Loss (VEL/SEL) were determined. The linear optical susceptibility $\chi^{(1)}$ increased with $T_{\text {ann. }}$. The influence of annealing temperatures on all of the non-linear refractive index $n_{2}$, the third-

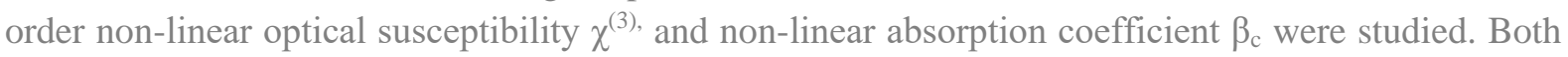
of the electrical susceptibility $\chi_{\mathrm{e}}$ and relative permittivity $\varepsilon_{\mathrm{r}}$ increased with $\mathrm{T}_{\mathrm{ann}}$ and had the highest value higher than $E_{\mathrm{g}}$. The dependence of density valence band, conduction band, and position of Fermi level $\mathrm{E}_{\mathrm{f}}$ were studied.
\end{abstract}

Keywords: $\mathrm{CdP}_{0.03} \mathrm{Te}_{0.97}$ thin film; thermal annealing; dielectric results; linear optical susceptibility; non-linear optical parameters and semiconducting results.

(C) 2021 by the authors. This article is an open-access article distributed under the terms and conditions of the Creative Commons Attribution (CC BY) license (https://creativecommons.org/licenses/by/4.0/).

\section{Introduction}

CdTe is II-VI crystalline compound with a zinc blende crystal structure and has a direct bandgap of $1.44 \mathrm{eV}$ [1] which is suitable for electronic applications such as photovoltaic devices [2] light-emitting diodes [3,4] solar cells [5,6] X-ray and gamma detectors [7] Field Effect Transistors (FETS) [8] Lasers [9] and non-linear integrated optical devices [10]. The structure of CdTe thin films was carried out by many authors [11-15]; it was found that CdTe thin films had a polycrystalline structure[11-12], and the annealing process increased the crystallinity of CdTe films [15,16]. The optical properties of CdTe thin films were studied [17$23]$ it was found that, the energy gap values were $(1.44-1.60 \mathrm{eV})[17](1.45-1.52 \mathrm{eV})[18]$ $1.534 \mathrm{eV}$ [19] (1.43-1.50 eV) [21] and also CdTe had a high absorption coefficient $\left(10^{4} \mathrm{~cm}^{-1}\right)$ 
$[22,23]$. The annealing effect on optical properties was investigated [24-28]; it was found that the annealing process decreased the energy gap of CdTe [27] and reduced both transmission and reflection for CdTe [28]. On the other hand, the doping effect on CdTe thin films' optical properties was studied [29-35]. It was found that Sn dopant increased absorption coefficient [29] Al, Sb dopant ratio decreased energy gap [31] band gap increased refractive index and extinction coefficient decreased with increasing $\mathrm{Ni}$ ratio in $\mathrm{Cd}_{1-\mathrm{x}} \mathrm{Ni}_{\mathbf{x}} \mathrm{Te}$ films [34]. The transmittance spectra decreased by the addition of $\mathrm{Cu}$ [35]. The increase in bandgap energy and the effect of annealing temperature on structure and optical properties of CdPTe thin films were studied [36]; it was found that the optical energy gap increased with annealing temperature.

This work investigates the annealing temperatures' effect on dielectric semiconducting results, Fermi level position, first-order optical susceptibility, and non-linear optical results for CdTe thin-film doped with phosphorus.

\section{Materials and Methods}

CdTe doped with phosphorus compound was synthesized by the direct fusion method. Mixtures of high purity elements (Cd, P, and Te) (99.999\%) in stoichiometric portions (obtained from Aldrich Chemical Co.) were used. The composition mixture was taken in a graphitized silica tube evacuated at a pressure of $10^{-5} \mathrm{kPa}$. The evacuated tube was then placed into a furnace whose temperature was raised gradually to $1000{ }^{\circ} \mathrm{C}$. During the synthesis, the molten material was shaken every $2 \mathrm{~h}$ to ensure homogeneity. Then the temperature of the furnace was kept at this temperature for $144 \mathrm{hs}$ and then cooled to room temperature. Thin cadmium telluride doped with phosphorus films was prepared by vacuum thermal evaporation on glass substrates using an Edward coating unit under pressure $10^{-5} \mathrm{kPa}$. Glass substrates were cleaned by a cleaning solution rinsed in distilled water than pure alcohol in an ultrasonic cleaner. Transmittance $(T)$ and reflectance $(R)$ of the as-deposited, annealed thin films at 100 and $200^{\circ} \mathrm{C}$ were measured at normal incidence using a Jasco (V-570) spectrophotometer from 500 to $2500 \mathrm{~nm}$. The thickness of the evaporated films was determined by a quartz thickness monitor and confirmed by multiple-beam interferometers.

\section{Results and Discussion}

\subsection{Dielectric, optical conductivity, and linear optical susceptibility results.}

The structure of these films with different annealing temperatures is illustrated in previous work [36]. The optical transmittance $\mathrm{T}$ and reflectance $\mathrm{R}$ were measured and discussed in previous work [36]. The single oscillator theory was expressed by WempleDiDomenico relationship [37]:

$$
n^{2}(E)-1=\frac{E_{o} \cdot E_{d}}{E_{o}^{2}-E^{2}}
$$

Where $\mathrm{n}$ is the refractive index values of these samples which are determined in previous work [36] $\mathrm{E}$ is the photon energy, $\mathrm{E}_{\mathrm{o}}$ is the oscillator energy, and $\mathrm{E}_{\mathrm{d}}$ is the dispersion energy. The values of $E_{o}$ and $E_{d}$ for all samples are shown in Table 1. 
Table 1. The determined values of $\mathrm{CdP}_{0.03} \mathrm{Te}_{0.97}$ film with different annealing temperatures such as lattice dielectric constant $\left(\varepsilon_{L}\right)$, Oscillation energy $\left(E_{o}\right)$, Dispersion energy $\left(E_{d}\right)$, the first order of moment $\left(M_{-1}\right)$, third order of moment $\left(M_{-3}\right)$, Field strength $(f)$, static refractive index $\left(n_{o}\right),\left(N / m^{*}\right)$, the density of conduction band $N_{c}$ $\left(\mathrm{cm}^{-3}\right)$, the density of valence band $N_{v}\left(\mathrm{~cm}^{-3}\right)$ and Fermi level position.

\begin{tabular}{|c|c|c|c|c|c|c|c|c|c|c|c|}
\hline Sample & $\begin{array}{l}\text { Lattice } \\
\text { dielectric } \\
\text { constant } \varepsilon_{L}\end{array}$ & $\begin{array}{l}\text { Oscillation } \\
\text { energy } E_{o} \\
(\mathrm{eV})\end{array}$ & $\begin{array}{l}\text { Dispersion } \\
\text { energy } E_{d} \\
(\mathrm{eV})\end{array}$ & $\begin{array}{l}M_{-1} \\
(\mathrm{eV})\end{array}$ & $\begin{array}{l}M_{-3} \\
(\mathrm{eV})\end{array}$ & $\begin{array}{l}\text { Field } \\
\text { strength } \\
(f)(\mathrm{eV})^{2}\end{array}$ & $n_{o}$ & $N / m *$ & $N_{C}$ & $N_{V}$ & $\begin{array}{l}\text { Fermi } \\
\text { Level } \\
\text { Position } \\
(\mathrm{eV})\end{array}$ \\
\hline $\begin{array}{l}\text { As- } \\
\text { deposited }\end{array}$ & 16.00 & 3.40 & 6.50 & 4.70 & 2.55 & 22.10 & 1.70 & $\begin{array}{l}2.1 \mathrm{E}+ \\
49 \\
\end{array}$ & $\begin{array}{l}7.18 \mathrm{E} \\
+22 \\
\end{array}$ & $\begin{array}{l}3.1 \mathrm{E}+ \\
21 \\
\end{array}$ & 0.11 \\
\hline $\begin{array}{l}\text { Annealed } \\
\text { at } 100^{\circ} \mathrm{C}\end{array}$ & 18.00 & 3.60 & 6.80 & 4.95 & 2.61 & 24.48 & 1.69 & $\begin{array}{l}2.8 \mathrm{E}+ \\
49\end{array}$ & $\begin{array}{l}1.15 \mathrm{E} \\
+23\end{array}$ & $\begin{array}{l}5.0 \mathrm{E}+ \\
21\end{array}$ & 0.15 \\
\hline $\begin{array}{l}\text { Annealed } \\
\text { at } 200^{\circ} \mathrm{C}\end{array}$ & 21.50 & 3.75 & 7.10 & 5.16 & 2.66 & 26.63 & 1.71 & $\begin{array}{l}1.5 \mathrm{E}+ \\
50\end{array}$ & $\begin{array}{l}1.64 \mathrm{E} \\
+23\end{array}$ & $\begin{array}{l}7.2 \mathrm{E}+ \\
21\end{array}$ & 0.19 \\
\hline
\end{tabular}

Figure 1 shows the relation of $n^{2}$ and $\lambda^{2}$ to determine the ratio of effective mass to carrier concentration using the following equation [38]:

$$
n^{2}=\varepsilon_{L}-\left(\frac{e N}{4 \pi c^{2} \varepsilon_{o} m^{*}}\right) \lambda^{2}
$$

Where $\varepsilon_{\mathrm{L}}$ is the lattice dielectric constant, $\varepsilon_{\mathrm{o}}$ is the permittivity of free space, e is the charge of the electron, $\mathrm{n}, \mathrm{k}$ are the linear refractive index and the absorption index of these films, respectively, which was determined in previous work [36] $\mathrm{N}$ is the free carrier concentration for $\mathrm{CdP}_{0.03} \mathrm{Te}_{0.97}$ film with different annealing temperatures and $\mathrm{c}$ is the speed of light so the values of $\mathrm{N} / \mathrm{m}^{*}$ are shown in Table 1 . From this table, the annealing temperatures affected the ratio of $\mathrm{N} / \mathrm{m}^{*}$ the high annealing temperature induces a higher number of free electrons. The values of the first order of moment $\mathrm{M}_{-1}$ and the third order of moment $\mathrm{M}_{-3}$ derived from the relations [38]:

$$
E_{o}^{2}=\frac{M_{-1}}{M_{-3}}
$$

Table 1 shows the values of $M_{-1}$ and $M_{-3}$ for these thin films. The oscillator strength (f) was calculated as following [39]:

$$
f=E_{o} \cdot E_{d}
$$

The values of $f$ are shown in Table 1 .

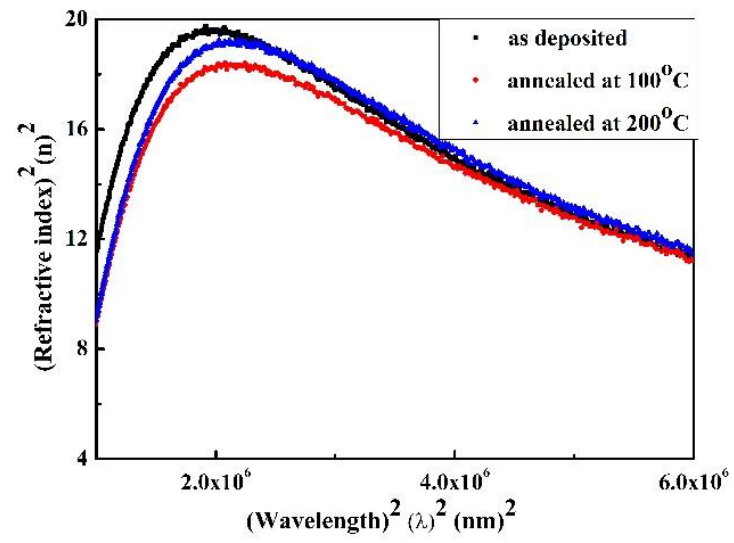

Figure 1. Relation of $\mathrm{n}^{2}$ and $\lambda^{2}$ for $\mathrm{CdP}_{0.03} \mathrm{Te}_{0.97}$ thin film with different annealing temperatures.

Another important parameter depending on both $E_{o}$ and $E_{d}$ is that static refractive index $\mathrm{n}_{\mathrm{o}}$, which was determined using the following equation [40]:

$$
n_{o}=\left[\left(E_{d} / E_{o}\right)+1\right]^{0.5}
$$


The values of $n_{0}$ for all these samples are shown in Table 1. Figure 2 represents the dependence of $\left(n^{2}-1\right)^{-1}$ on $h v$ for these thin films. From this figure, it was seen that all these samples had the same behavior, and the values of $\left(n^{2}-1\right)^{-1}$ increased with annealing temperatures.

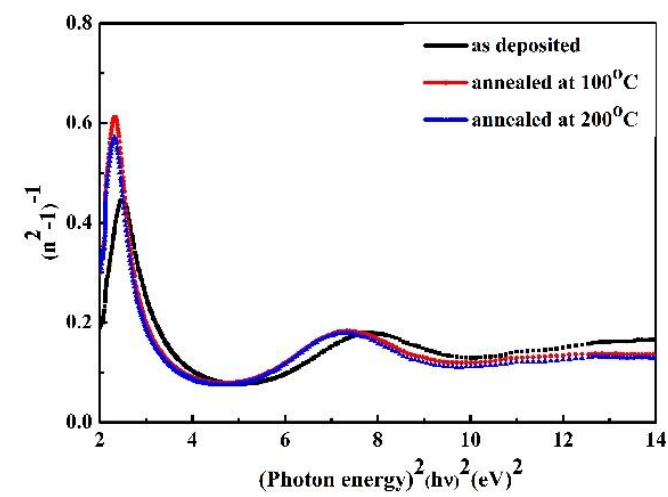

Figure 2. $(\mathrm{n}-1)^{-1}$ vs. $h v$ for $\mathrm{CdP}_{0.03} \mathrm{Te}_{0.97}$ thin film with different annealing temperatures.

The dielectric loss $\left(\varepsilon^{\prime}\right)$ and dielectric tangent loss $\left(\varepsilon^{\prime \prime}\right)$ for these films were calculated as following [41]:

$$
\begin{gathered}
\varepsilon^{\prime}=\left(n^{2}+k^{2}\right) \\
\varepsilon^{\prime \prime}=\left[\left(n^{2}+k^{2}\right)^{2}-\left(n^{2}-k^{2}\right)^{0.5}\right]
\end{gathered}
$$

Figure 3(a,b) shows the relation between both $\varepsilon^{\prime}$ and $\varepsilon^{\prime \prime}$ and $\mathrm{h} v$ for $\mathrm{CdP}_{0.03} \mathrm{Te} 0.97$ film with different annealing temperatures. From this figure, it was seen that, at energy less that energy gap, the values of both of $\varepsilon^{\prime}$ and $\varepsilon^{\prime \prime}$ decreased with annealing temperatures for all studied samples, and the peak maximum values position decreased with increasing annealing temperatures, this is due to the increasing of electron motilities with annealing temperatures.
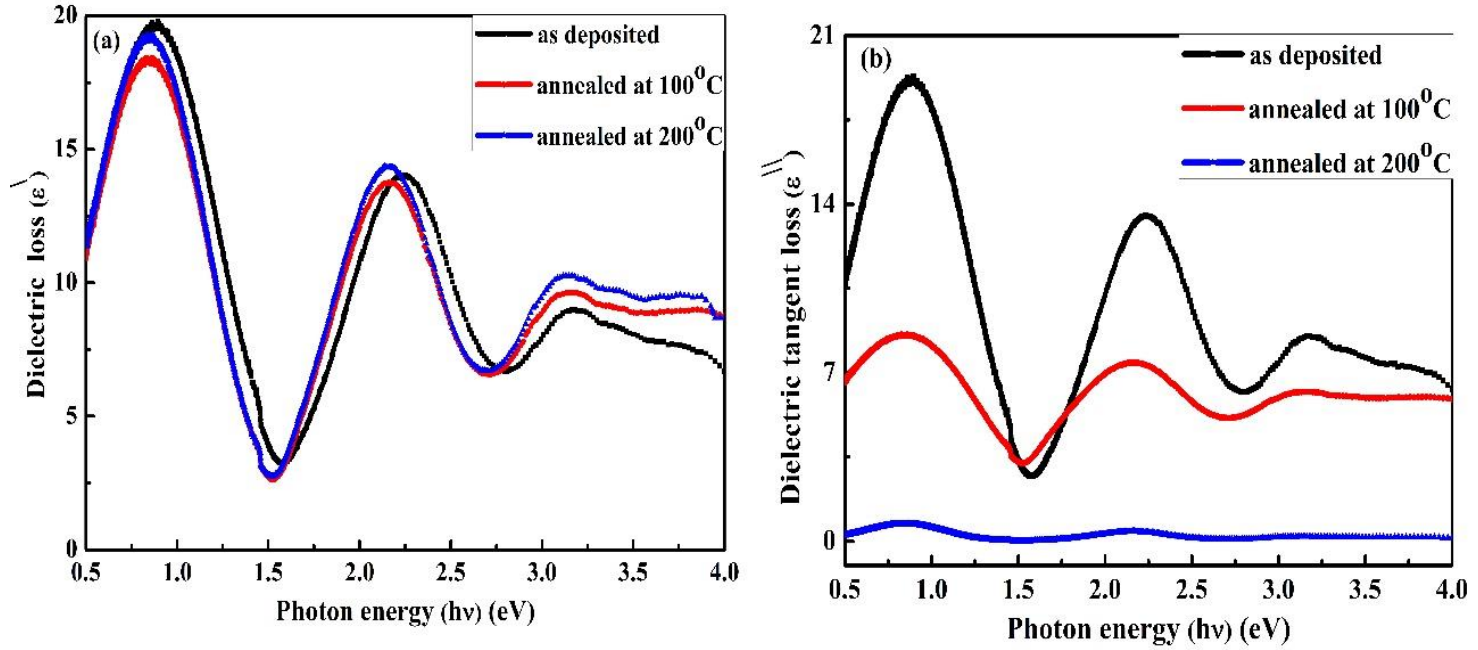

Figure 3. (a) The dependence of $\varepsilon^{\prime}$; (b) $\varepsilon^{\|}$on $h v$ for $\mathrm{CdP}_{0.03} \mathrm{Te}_{0.97}$ film with different annealing temperatures.

The optical conductivity was calculated from the following equations [42]:

$$
\begin{gathered}
\sigma_{1}=\left(\frac{\varepsilon^{\prime \prime} \cdot c}{2 \lambda}\right) \\
\sigma_{2}=\frac{\left(1-\varepsilon^{\prime}\right) \cdot c}{4 \lambda}
\end{gathered}
$$


The dependence of $\sigma_{1}$ and $\sigma_{2}$ on $h v$ for these films is shown in Figure 4(a,b). The behavior of both $\sigma_{1}$ and $\sigma_{2}$ for all these studied films is the same with $h v$ and increase with $h v$ for all these samples.
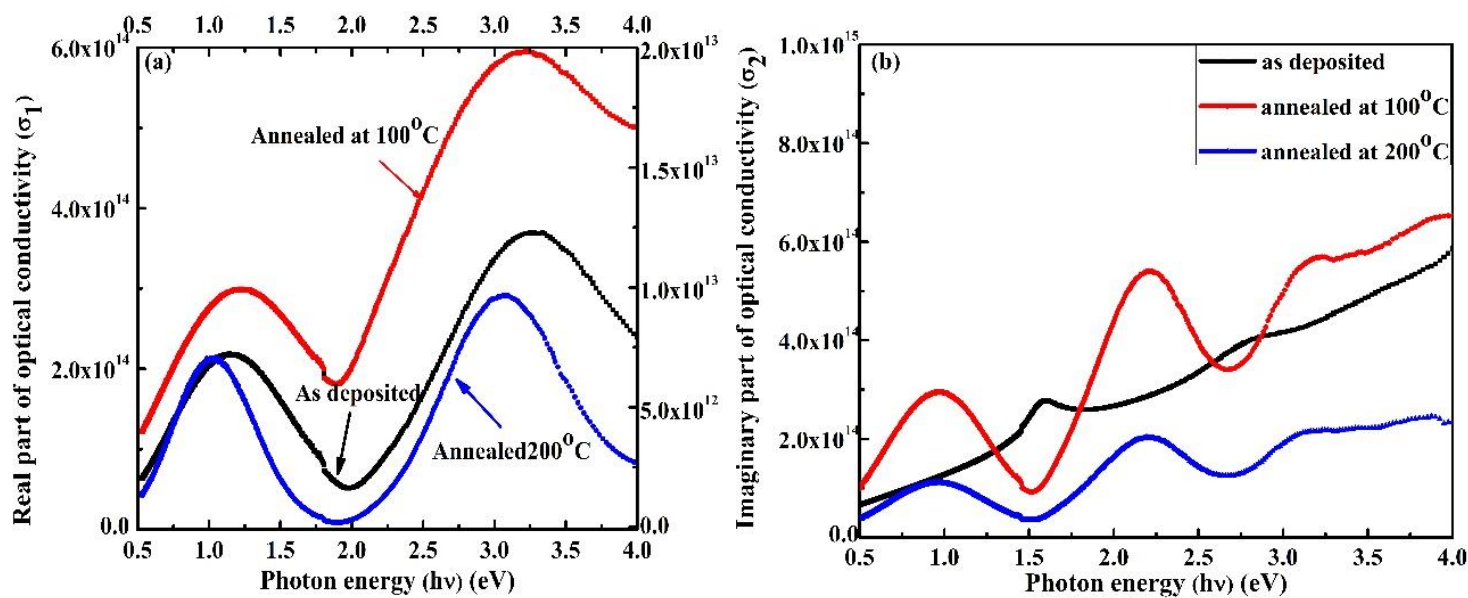

Figure 4. (a) The dependence of $\sigma_{1}$; (b) $\sigma_{2}$ on $h v$ for $\mathrm{CdP}_{0.03} \mathrm{Te}_{0.97}$ film with different annealing temperatures.

The values of Volume Energy Loss Function (VELF) and Surface Energy Loss Function (SELF) for these films were determined optically as following [38]:

$$
\begin{gathered}
\text { VELF }=\frac{\varepsilon^{\prime \prime}}{\varepsilon^{\prime 2}+\varepsilon^{\prime \prime 2}} \\
S E L F=\frac{\varepsilon^{\prime \prime}}{\left(\varepsilon^{\prime}+1\right)^{2}+\varepsilon^{\prime \prime 2}}
\end{gathered}
$$

The dependence of VELF/SELF on annealing temperatures is shown in Figure 5(a). $\chi^{(1)}$, which describes the effect of wave length on films optical response, was calculated as [43]:

$$
\chi^{(1)}=\frac{\left(n^{2}-1\right)}{4 \pi}
$$

The relation between $\chi^{(1)}$ and $\mathrm{h} v$ for $\mathrm{CdP}_{0.03} \mathrm{Te}_{0.97}$ thin film with different annealing temperatures is shown in Figure 5(b). From this figure, it was seen that the linear optical susceptibility $\chi^{(1)}$ increased with annealing temperatures, and the values of $\chi^{(1)}$ had maximum values higher than $\mathrm{Eg}_{\mathrm{g}}$. This means that there is a possibility of a wide change in optical properties by thermal annealing.
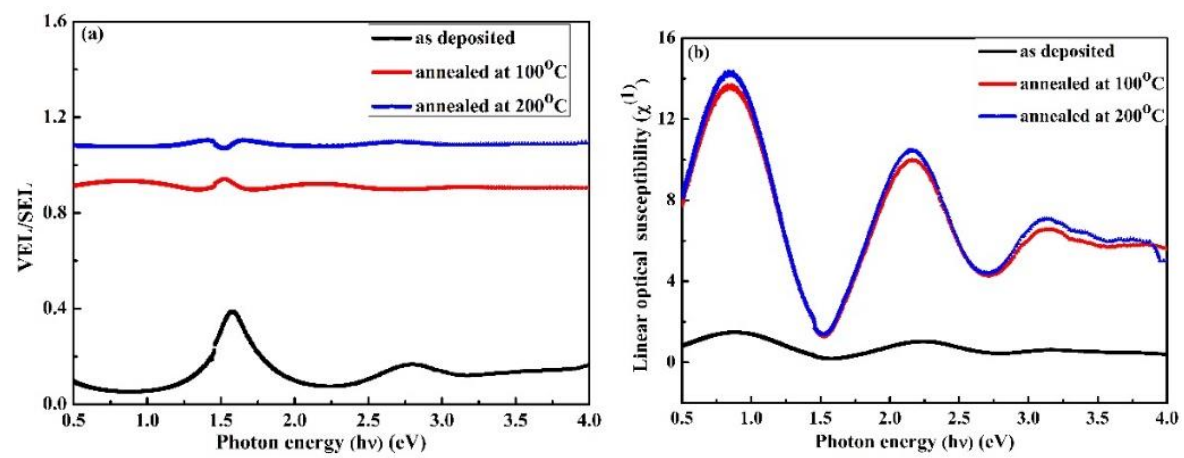

Figure 5. (a) Dependence of $V E L / S E L$; (b) $\chi^{(l)}$ on $h v$ for $\mathrm{CdP}_{0.03} \mathrm{Te}_{0.97}$ film with different annealing temperatures.

\subsection{Non-linear optical properties.}

The non-linear refractive index $\mathrm{n}_{2}$, which can be explained as when intense light go through media the trftactive index change, which is non-linear phenomena[44] $\mathrm{n}_{2}$ was determined from the following simple equation [45-46]: 


$$
n_{2}=\left(12 \pi \chi^{(3)}\right) / n_{o}
$$

The dependence of $\mathrm{n}_{2}$ on wavelength for $\mathrm{CdP}_{0.03} \mathrm{Te} 0.97$ thin film with different annealing temperatures is shown in figure 6(a). The values of $n_{2}$ decrease with wavelength and annealing temperature for all these studied samples; this is due to increased transmittance with annealing temperature [36, leading to a decrease of propagated light and may be attributed to the degree increase of homogeneity of the thin film. An important parameter to assess the degree of nonlinearities in the third-order non-linear optical susceptibility $\chi^{(3)}$ which was determined using the following equation [47]:

$$
\chi^{(3)}=A\left[\frac{E_{o} \cdot E_{d}}{4 \pi\left(E_{o}^{2}-(h v)^{2}\right)}\right]^{4}
$$

Where $\mathrm{A}=1.7 \times 10^{-10}$ e.s.u [45]. The dependence of $\chi^{(3)}$ on $\mathrm{h} v$ for $\mathrm{CdP}_{0.03} \mathrm{Te}_{0.97}$ film with different annealing temperatures is shown in Figure 6(b). It was noticed that the behavior of $\chi^{(3)}$ is the same for all the studied sample the values of $\chi^{(3)}$ increase with $h v$ this is due to when $\mathrm{h} v$ increases, the deflection of the incident light beam increases and the values of $\chi^{(3)}$ decrease with annealing temperature this could attribute to the variation of free carrier concentration which leads to the increase of electrons mobility with annealing temperatures. On the other hand, another important non-linear parameter such as the non-linear absorption coefficient $\beta_{c}$, which determined as following [48]:

$$
\beta_{c}=\frac{48 \cdot \pi^{3} \cdot \chi^{(3)}}{n^{2} \cdot c \cdot \lambda}
$$

The values of $\beta_{c}$ increase with $h v$ for all these samples, as shown in Figure 6(c), because of the higher values of hv a large number of excited electrons overcoming the bandgap.
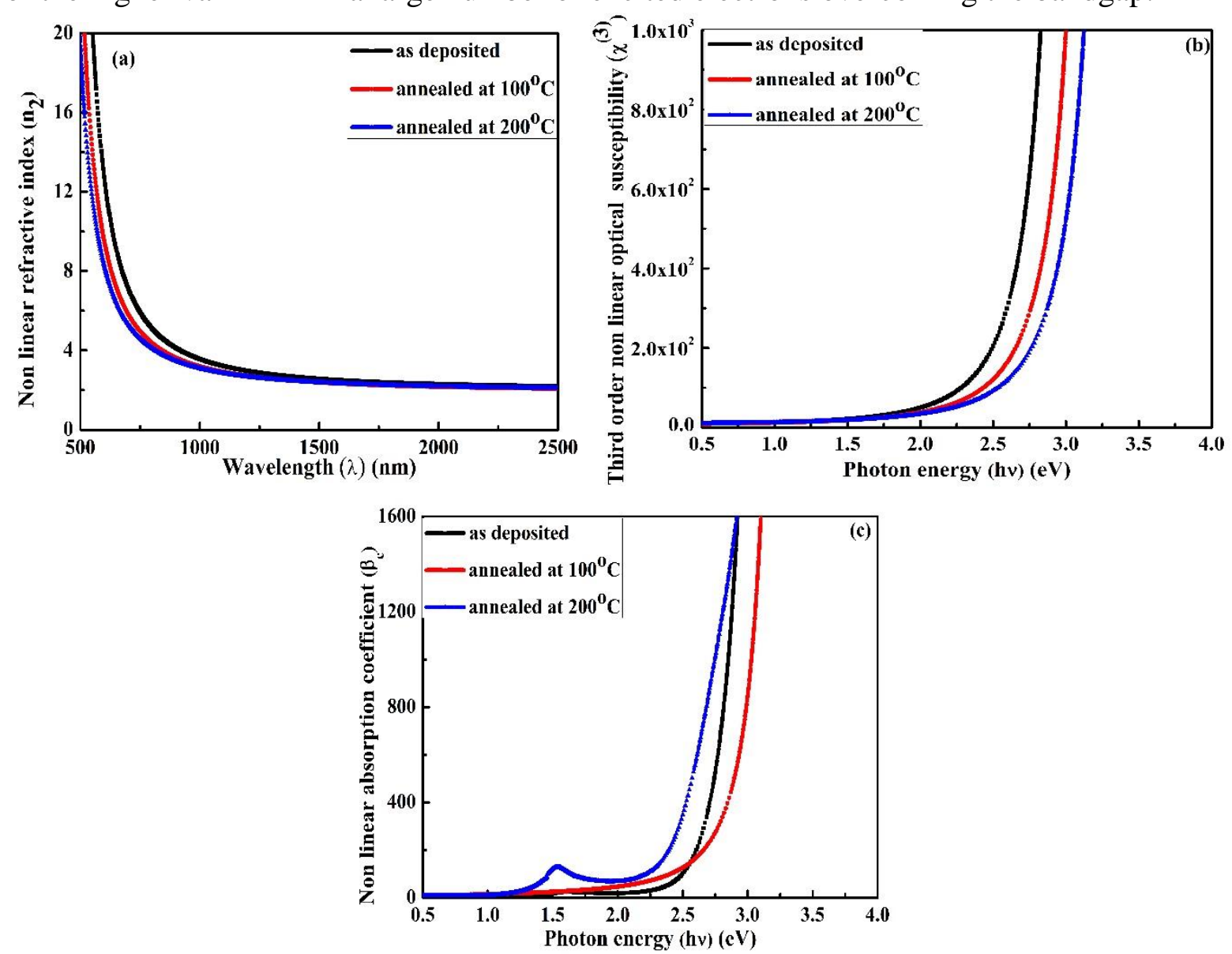

Figure 6. (a) Relation between $n_{2}$ and $\lambda$, the influence of $h v$ on both of; (b) $\chi^{(3)} ; \mathbf{c} \beta_{c}$ for $\mathrm{CdP}_{0.03} \mathrm{Te}_{0.97}$ film with different annealing temperatures. 


\subsection{Electrical results.}

Electrical susceptibility $\chi(\mathrm{e})$ was determined using the following relation [49]:

$$
\chi_{(e)}=\frac{\left(n^{2}-k^{2}-\varepsilon_{o}\right)}{4 \pi}
$$

Figure 7(a) shows $\chi_{e}$ vs. hv of these investigated samples. From this figure, it is clear that the values of $\chi_{\mathrm{e}}$ increase with annealing temperatures. This is due to the increasing electron mobility. The relative permittivity $\varepsilon_{\mathrm{r}}$ was calculated using the following relation [50]:

$$
\varepsilon_{r}=\left(\chi_{e}+1\right)
$$

The relation between relative permittivity $\varepsilon_{\mathrm{r}}$ and wavelength for $\mathrm{CdP}_{0.03} \mathrm{Te}_{0.97}$ thin film with different annealing temperatures is shown in Figure 7(b). It was found that $\varepsilon_{\mathrm{r}}$ had strongly affected by annealing temperatures; this could be attributed to the electron mobility changes with annealing temperature.
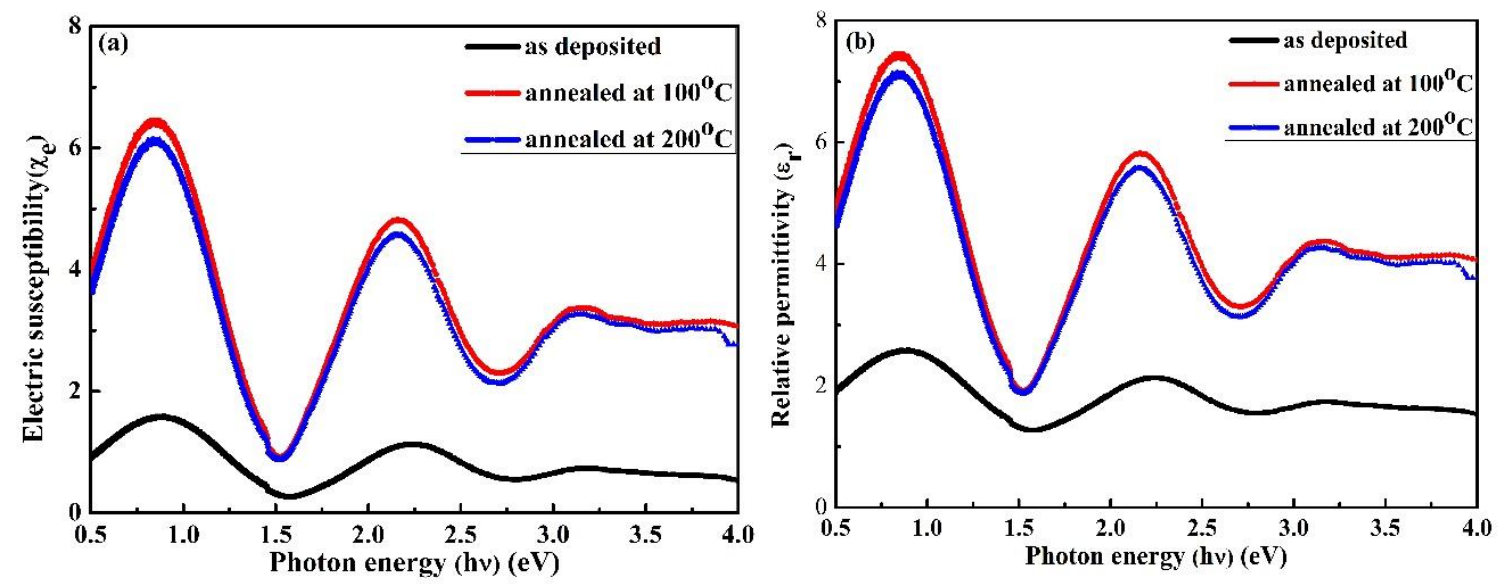

Figure 7. (a) The dependence of electrical susceptibility $\chi_{(\mathrm{e})}$; (b) relative permittivity $\varepsilon_{r}$ on hv for $\mathrm{CdP}_{0.03} \mathrm{Te}_{0.97}$ film with different annealing temperatures.

\subsection{Semiconducting and electronic results.}

Both $\mathrm{N}_{\mathrm{v}}$ and $\mathrm{N}_{\mathrm{c}}$ play very important rules examination of the linear optical transition and non-linear optical properties. $\mathrm{N}_{\mathrm{v}}$ and $\mathrm{N}_{\mathrm{c}}$ are calculated as following [51]:

$$
\begin{gathered}
N_{v}=2\left[\left(2 \pi m^{*}{ }_{h} K T\right) / h^{2}\right]^{3 / 2} \\
N_{c}=2\left[\left(2 \pi m^{*}{ }_{e} K T\right) / h^{2}\right]^{3 / 2}
\end{gathered}
$$

where $N_{v}$ and $N_{c}$ are the density of states for both valence and conduction bands respectively, effective mass of electrons in $(\mathrm{CdTe}) \mathrm{m}_{\mathrm{e}}{ }_{\mathrm{e}}=0.11$ [52] effective mass of holes in $(\mathrm{CdTe}) \mathrm{m}_{\mathrm{h}}{ }_{\mathrm{h}}=$ 0.18 [52] effective mass of holes in $(\mathrm{CdP}) \mathrm{m}^{*}{ }_{\mathrm{h}}=0.4$ [53] effective mass of electrons in $(\mathrm{CdP})$ $\mathrm{m}_{\mathrm{h}}{ }_{\mathrm{h}}=0.05$ [53] and $\mathrm{K}$ is a Boltzmann constant. The determined values for both $\mathrm{N}_{\mathrm{v}}, \mathrm{N}_{\mathrm{c}}$ are shown in table 1. Another important factor that was determined theoretically is the position of Fermi level [54]:

$$
E_{f}=\left(\frac{K T}{q}\right) \cdot \ln \left(N_{c} / N_{v}\right)
$$

The values of Fermi level position for these investigated thin films are shown in Table 1. 


\section{Conclusions}

The values of $E_{d}$ and $E_{o}$ increased with annealing temperatures for $\mathrm{CdP}_{0.03} \mathrm{Te}_{0.97}\left(\mathrm{E}_{\mathrm{d}}\right.$ from 6.50 to $7.10 \mathrm{eV}$ ), and also $E_{o}$ had the values from (3.4 to $\left.3.75 \mathrm{eV}\right)$. The values of N/m* increased with annealing temperatures $T_{\text {ann, }}$, which increased free carrier. The values of $\mathrm{M}_{-1}$ and M-3 also increased with increasing $T_{\text {ann. Both of }} \varepsilon^{\prime}$ and $\varepsilon^{\prime \prime}$ increased with $h v$, and the maximum values decreased with increasing $T_{a n n}$ due to increased electron mobility with increasing $T_{a n n}$. Both $\sigma_{1}$ and $\sigma_{2}$ decreased with $T_{a n n} . \chi^{(1)}$ increased with $T_{a n n}$ due to increasing carrier concentration. The values of $\mathrm{n}_{2}$ increased with $\lambda$ for all these samples, while $\chi^{3}$ increased with $\mathrm{h} v$. This means that these samples could change their optical properties by changing wavelength and applied field. The non-linear absorption coefficient $\left(\beta_{c}\right)$ decreased with $T_{a n n}$, whiles both of the $\chi_{\mathrm{e}}$ and $\varepsilon_{\mathrm{r}}$ increases with $\mathrm{T}_{\mathrm{ann}}$ and had the highest value higher than the energy gap. The annealing temperatures affected the values of both $N_{v}$ and $N_{c}$, while $E_{f}$ affected slightly with $\mathrm{T}_{\mathrm{ann}}$.

\section{Funding}

This research received no external funding.

\section{Acknowledgments}

This research has no acknowledgment.

\section{Conflicts of Interest}

The authors declare no conflict of interest.

\section{References}

1. Taki, M. Structural and optical properties of Cadmium Telluride $\mathrm{Cd}_{\mathrm{x}} \mathrm{Te}_{1-\mathrm{x}}$ thin film by evaporate technique. International Journal of Application or Innovation in Engineering \& Management 2013, 2, 413-417.

2. Curtin, A.M.; Vail, C.A.; Buckley, H.L. CdTe in thin film photovoltaic cells: Interventions to protect drinking water in production and end-of-life. Water-Energy Nexus 2020, 3, 15-28, https://doi.org/10.1016/j.wen.2020.03.007.

3. Li, G.; Chen, T.-B.; Zhao, Z.; Ling, L.; Li, Q.; Chen, S. Green and high yield synthesis of CdTe @ Hydrotalcite nanocrystals with enhanced photoluminescence stability toward white light emitting diodes. J. Lumin. 2020, 228, 117625, https://doi.org/10.1016/j.jlumin.2020.117625.

4. Feng, H.; Song, J.; Song, B.; Lin, Q.; Shen, H.; Li, L.S.; Wang, H.; Du, Z. Highly efficient near-infrared lightemitting diodes based on chloride treated CdTe/CdSe type-II quantum dots. Frontiers in chemistry 2020, 8 , 266, https://doi.org/10.3389/fchem.2020.00266.

5. Harif, M.N.; Rahman, K.S.; Rosly, H.N.; Chelvanathan, P.; Doroody, C.; Misran, H.; Amin, N. An approach to alternative post-deposition treatment in CdTe thin films for solar cell application. Superlattices Microstruct. 2020, 147, 106687, https://doi.org/10.1016/j.spmi.2020.106687.

6. Himanshu; Patel, S.L.; Thakur, A.; Kannan, M.D.; Dhaka, M.S. Impact of Bi doping on CdTe thin films: Thermal annealing evolution of physical properties for solar cell absorber layer applications. Thin Solid Films 2020, 709, 138004, https://doi.org/10.1016/j.tsf.2020.138004.

7. Maslyanchuk, O.; Solovan, M.; Brus, V.; Maryanchuk, P.; Maistruk, E.; Fodchuk, I.; Gnatyuk, V. Charge transport features of CdTe-based X- and $\gamma$-ray detectors with Ti and TiOx Schottky contacts. Nuclear Instruments and Methods in Physics Research Section A: Accelerators, Spectrometers, Detectors and Associated Equipment 2021, 988, 164920, https://doi.org/10.1016/j.nima.2020.164920.

8. Rizzo, A.; Li, Y.; Kudera, S.; Della Sala, F.; Zanella, M.; Parak, W.J.; Cingolani, R.; Manna, L.; Gigli, G. Blue light emitting diodes based on fluorescent CdSeZnS nanocrystals. Appl. Phys. Lett. 2007, 90, 051106, https://doi.org/10.1063/1.2426899. 
9. Wu, B.J.; Kuo, L.H.; DePuydt, J.M.; Haugen, G.M.; Haase, M.A.; Salamanca-Riba, L. Growth and characterization of II-VI blue light-emitting diodes using short period superlattices. Appl. Phys. Lett. 1996, 68, 379-381, https://doi.org/10.1063/1.116691.

10. Chander, S.; Dhaka, M.S. Optimization of physical properties of vacuum evaporated CdTe thin films with the application of thermal treatment for solar cells. Mater. Sci. Semicond. Process. 2015, 40, 708-712, https://doi.org/10.1016/j.mssp.2015.07.063.

11. Papikyan, A.K.; Gevorgyan, V.A.; Mangasaryan, N.R.; Gladyshev, P.P. Characterization of vacuum flash evaporated CdTe thin films for solar cell application. Journal of Physics: Conference Series 2018, 945, 012013, https://doi.org/10.1088/1742-6596/945/1/012013.

12. Ehsani, M.H.; Rezagholipour Dizaji, H.; Azizi, S.; Ghavami Mirmahalle, S.F.; Hosseini Siyanaki, F. Optical and structural properties of cadmium telluride films grown by glancing angle deposition. Phys. Scr. 2013, 88, 025602, https://doi.org/10.1088/0031-8949/88/02/025602.

13. Huimin, C.; Fuqiang, G.; Baohua, Z. Properties of CdTe nanocrystalline thin films grown on different substrates by low temperature sputtering. Journal of Semiconductors 2009, 30, 053001, https://doi.org/10.1088/1674-4926/30/5/053001.

14. Khan, Z.R.; Zulfequar, M.; Khan, M.S. Structural, optical, photoluminescence, dielectric and electrical studies of vacuum-evaporated CdTe thin films. Bull. Mater. Sci. 2012, 35, 169-174, https://doi.org/10.1007/s12034-012-0274-X.

15. Lai, H.; Li, K.; Wu, L.; Xu, H.; Li, C.; Li, C.; Zhang, J.; Hao, X.; Feng, L. Impact of In Situ Annealing Time on CdTe Polycrystalline Film and Device Performance. J. Electron. Mater. 2019, 48, 853-860, https://doi.org/10.1007/s11664-018-6792-6.

16. Geethalakshmi, D.; Muthukumarasamy, N. Effect Of Annealing On Structural And Optical Properties Of CdTe Thin Films. Journal of Nanoscience and Nanotechnology 2012, 1, 23-29.

17. Kulkarni, R.; Rondiya, S.; Pawbake, A.; Waykar, R.; Jadhavar, A.; Jadkar, V.; Bhorde, A.; Date, A.; Pathan, H.; Jadkar, S. Structural and Optical Properties of CdTe Thin Films Deposited Using RF Magnetron Sputtering. Energy Procedia 2017, 110, 188-195, https://doi.org/10.1016/j.egypro.2017.03.126.

18. Khairnar, U.P.; Bhavsar, D.S.; Vaidya, R.U.; Bhavsar, G.P. Optical properties of thermally evaporated cadmium telluride thin films. Mater. Chem. Phys. 2003, 80, 421-427, https://doi.org/10.1016/S02540584(02)00336-X.

19. Lalitha, S.; Karazhanov, S.Z.; Ravindran, P.; Senthilarasu, S.; Sathyamoorthy, R.; Janabergenov, J. Electronic structure, structural and optical properties of thermally evaporated CdTe thin films. Physica B: Condensed Matter 2007, 387, 227-238, https://doi.org/10.1016/j.physb.2006.04.008.

20. Hakeem, A.M.A.; Ali, H.M.; El-Raheem, M.M.A.; Hasaneen, M.F. Study the effect of type of substrates on the microstructure and optical properties of CdTe Thin Films. Optik 2021, 225, 165390, https://doi.org/10.1016/j.ijleo.2020.165390.

21. Matt, M.H.; Shivappa, N.C.; Patel, R.; Jeetendra, S. Thickness Dependent Optical Parameters of Vacuum Evaporated Cadmium Telluride Thin Films. International Journal of Renewable Energy \& Biofuels 2014, 2014, 1-8, https://doi.org/10.5171/2014.791671.

22. Alnajjar, A.A.; Al-Shaikley, F.Y.; Alias, M.F.A. Optical Properties and photoconductivity of Undoped and n-doped CdTe thin films. Journal of Electron Devices 2012, 16, 1306.

23. A. El-Amin, A.; Ibrahim, A. Structural, Optical, and Electrical Properties of CdTe Thin Films Deposited by Glancing Angle Deposition. Current Nanoscience 2012, $8, \quad$ 783-789, https://doi.org/10.2174/157341312802884508.

24. Mazur, T.M.; Makhniy, V.P.; Prokopiv, V.V.; Slyotov, M. Thermal Annealing Effect on Optical Properties of the Cadmiun Telluride Films. J. Nano and Electron. Phys. 2017, 9, 05047-05049, https://doi.org/10.21272/jnep.9(5).05047.

25. Mahato, S.; KumarKar, A. The effect of annealing on structural, optical and photosensitive properties of electrodeposited cadmium selenide thin films. J. Scie. Advan.Mater. Devic. 201, 2, 165-171, https://doi.org/10.1016/j.jsamd.2017.04.001.

26. Ismail, R.A. Effect of rapid thermal annealing on properties of thermally evaporated nanostructured CdTe thin film treated with $\mathrm{CdCl}_{2}$. Materials Science in Semiconductor Processing 2012, 15, 159-164, https://doi.org/10.1016/j.mssp.2011.10.005.

27. Tanushevski, A.; Sokolovski, D. Structural and optical properties of CdTe thin films obtained by electrodeposition. 2017; 149-154. 
28. Rusu, G.G. On the electrical and optical properties of nanocrystalline CdTe thin films. Journal of Optoelectronics and Advanced Materials 2001, 3, 861-866.

29. Sayeed, M.A.; Rouf, H.K. Effect of Zn-doping on the structural, optical and electrical properties of thermally vacuum evaporated CdTe thin films. Surfaces and Interfaces 2021, 23, 100968, https://doi.org/10.1016/j.surfin.2021.100968.

30. Rusu, G. Structural, electronic transport and optical properties of Zn-doped CdTe thin films. Journal of Optoelectronics and Advanced Materials 2006, 8, 931-935.

31. Al-Douri, A.A.J.; Al-Shakily, F.Y.; Alias, M.F.A.; Alnajjar, A.A. Optical Properties of Al- and Sb-Doped CdTe Thin Films. Advances in Condensed Matter Physics 2010, 2010, 947684, https://doi.org/10.1155/2010/947684.

32. Goyal, S.; Chauhan, R.P. Effect of $\mathrm{Ar}^{+}$ion implantation on the properties of electrodeposited CdTe thin films. Bull. Mater. Sci. 2018, 41, 131, https://doi.org/10.1007/s12034-018-1649-4.

33. de Moure-Flores, F.; Quiñones-Galván, J.G.; Guillén-Cervantes, A.; Santoyo-Salazar, J.; HernándezHernández, A.; Olvera, M.d.l.L.; Zapata-Torres, M.; Meléndez-Lira, M. Structural and optical properties of $\mathrm{Cu}$-doped CdTe films with hexagonal phase grown by pulsed laser deposition. AIP Advances 2012, 2, 022131 , https://doi.org/10.1063/1.4721275.

34. Mahmood, A.; Aziz, U.; Rashid, R.; Shah, A.; Ali, Z.; Raza, Q.; Raffi, M.; Shakir, I. Exploration of optical behavior of Cd1- xNixTe thin films by spectroscopic ellipsometry. Materials Research Express 2014, 1 , 046409, https://doi.org/10.1088/2053-1591/1/4/046409.

35. Marwoto, P.; Made, D.P.N.; Sugianto; Wibowo, E.; Othaman, Z.; Astuti, S.Y.; Aryani, N.P. Preliminary study of CdTe and CdTe:Cu thin films nanostructures deposited by using DC magnetron sputtering. AIP Conf. Proc. 2013, 1555, 48-52, https://doi.org/10.1063/1.4820991.

36. Gad, S.A.; Moustafa, A.M. Effect of Annealing Temperature on the Structural and Optical Properties and Effect of Thickness on the Electrical Properties of Phosphorus Doped CdTe. Journal of Inorganic and Organometallic Polymers and Materials 2016, 26, 147-153, https://doi.org/10.1007/s10904-015-0294-2.

37. Ali, A.I.; Ammar, A.H.; Abdel Moez, A. Influence of substrate temperature on structural, optical properties and dielectric results of nano- $\mathrm{ZnO}$ thin films prepared by Radio Frequency technique. Superlattices Microstruct. 2014, 65, 285-298, https://doi.org/10.1016/j.spmi.2013.11.007.

38. Gad, S.A.; Moez, A.A. Enhanced Optical Conductivity, Nonlinear Optical and Semiconducting Properties of Mg1-xCuxO/PMMA Nanocomposite. Journal of Inorganic and Organometallic Polymers and Materials 2020, 30, 469-476, https://doi.org/10.1007/s10904-019-01205-0.

39. Wemple, S.H.; DiDomenico, M. Optical Dispersion and the Structure of Solids. Phys. Rev. Lett. 1969, 23, 1156-1160, https://doi.org/10.1103/PhysRevLett.23.1156.

40. Anshu, K.; Sharma, A. Study of Se based quaternary $\mathrm{SePb}(\mathrm{Bi}, \mathrm{Te})$ chalcogenide thin films for their linear and non-linear optical properties. Optik 2016, 127, 48-54, https://doi.org/10.1016/j.ijleo.2015.09.228.

41. Moez, A.A.; Ali, A.I. Influence of exposure time of LASER radiations on structural, optical, non-linear optical and dielectric results of Sb2Se3 nanofilms. Journal of Materials Science: Materials in Electronics 2021, 32, 1303-1315, https://doi.org/10.1007/s10854-020-04903-5.

42. Ammar, A.H.; Farid, A.M.; Seyam, M.A.M. Heat treatment effect on the structural and optical properties of AgInSe2 thin films. Vacuum 2002, 66, 27-38, https://doi.org/10.1016/S0042-207X(01)00417-1.

43. Fritz, S.E.; Kelley, T.W.; Frisbie, C.D. Effect of Dielectric Roughness on Performance of Pentacene TFTs and Restoration of Performance with a Polymeric Smoothing Layer. The Journal of Physical Chemistry B 2005, 109, 10574-10577, https://doi.org/10.1021/jp044318f.

44. Stolen, R.H.; Ashkin, A. Optical Kerr effect in glass waveguide. Appl. Phys. Lett. 1973, 22, 294-296, https://doi.org/10.1063/1.1654644.

45. Ticha, H.; Tichy, L. Semiempirical relation between non-linear susceptibility (refractive index), linear refractive index and optical gap and its application to amorphous chalcogenides. J. Optoelectron. Adv. Mater. 2002, 4, 381-386.

46. Zhou, P.; You, G.; Li, J.; Wang, S.; Qian, S.; Chen, L. Annealing effect of linear and non-linear optical properties of Ag:Bi2O3 nanocomposite films. Opt. Express 2005, 13, 1508-1514, https://doi.org/10.1364/opex.13.001508.

47. Ziabari, A.A.; Ghodsi, F.E. Optoelectronic studies of sol-gel derived nanostructured CdO-ZnO composite films. J. Alloys Compd. 2011, 509, 8748-8755, https://doi.org/10.1016/j.jallcom.2011.06.050.

48. Beata, D.; Bouchta, S.; Xuan Nguyen, P.; Waclaw, B. Nonlinear optical properties in ZnSe crystals. In Proceedings of Proc.SPIE 2001, 4412, 373-341, https://doi.org/10.1117/12.435856. 
49. Gupta, V.; Mansingh, A. Influence of postdeposition annealing on the structural and optical properties of sputtered zinc oxide film. J. Appl. Phys. 1996, 80, 1063-1073, https://doi.org/10.1063/1.362842.

50. Braslavsky, S.E. Glossary of terms used in photochemistry, 3rd edition (IUPAC Recommendations 2006). Pure Appl. Chem. 2007, 79, 293-465, https://doi.org/10.1351/pac200779030293.

51. Gad, S. A; Abdel Moez A. Enhanced Optical Conductivity, Nonlinear Optical and Semiconducting Properties of $\mathrm{Mg}_{1-\mathrm{x}} \mathrm{Cu}_{\mathrm{x}} \mathrm{O}$ /PMMA Nanocomposite. J. Inorg. Organomet.Polym. Mater. 2020, 30, 469-476, https://doi.org/10.1007/s10904-019-01205-0.

52. Long, F.; Hagston, W.E.; Harrison, P.; Stirner, T. The structural dependence of the effective mass and Luttinger parameters in semiconductor quantum wells. J. Appl. Phys. 1997, 82, 3414-3421, https://doi.org/10.1063/1.365657.

53. Gelten, M.J.; van Lieshout, A.; van Es, C.; Blom, F.A.P. Optical properties of $\mathrm{Cd}_{2} \mathrm{P}_{3}$, Sold. Stat. Phys. 1978, $11,227-237$.

54. Gad, S.A.; Mahmoud, G.M.; Abdel Moez, A. unable Non-linear Optical, Semiconducting and Dielectric Properties of $\operatorname{In}_{1-\mathrm{x}} \mathrm{MnxSe}$ Thin Films, J. Electron. Mater. 2019, 48, 5176-5183, https://doi.org/10.1007/s11664-019-07331-2. 